\title{
Formulation and quality evaluation of aglutenics biscuits supplimented with rice bran for coeliac patients
}

Sadaf Javaria ${ }^{1}$, Aiman Karim ${ }^{1}$, Muhammad Waqas ${ }^{1 *}$, Saeeda Raza ${ }^{2}$, Amer Mumtaz ${ }^{2}$ and Kashif Waseem ${ }^{1}$

1. Faculty of Agriculture, Gomal University, Dera Ismail Khan-Pakistan

2. National Agricultural Research Center, Islamabad-Pakistan

*Corresponding author's email: Waqasgandapur404@gmail.com

Citation

Sadaf Javaria, Aiman Karim, Muhammad Waqas, Saeeda Raza, Amer Mumtaz and Kashif Waseem. Formulation and quality evaluation of aglutenics biscuits supplimented with rice bran for coeliac patients. Pure and Applied Biology. Vol. 6, Issue 4, pp1283-1296. http://dx.doi.org/10.19045/bspab.2017.600137

\begin{tabular}{llll}
\hline \hline Received: 16/02/2017 & Revised: 04/10/2017 & Accepted: 07/10/2017 & Online First: 16/10/2017 \\
\hline \hline
\end{tabular}

Abstract

Coeliac disease is a chronic disorder of intestine in which patients cannot bear gluten, a wheat protein. There is no medication of this disease instead of using gluten free food. Moreover, coeliac patients use foods with low fiber and find food products with poor quality, hence generally face the problems of constipation and malnutrition. To cope up this problem the present research was designed. Gluten free biscuits developed with rice, maize and chickpea flours supplemented with 5\%, 10\% and 15\% stabilized rice bran (SBR) packed in HDPE in the experiment to find the higher quality and more nutritional gluten free biscuit formulations. The rice bran was stabilized with dry heat treatment before supplementation. Physicochemical analysis of biscuits revealed that moisture, ash, crude protein, fiber and thickness were significantly increased with the increment of SBR. While, width and spread factor of biscuits were decreased with the increased levels of SBR. Sensory evaluation of biscuits revealed that biscuit supplemented with 5-10\% SBR were liked by the panelists. Therefore, it can be concluded from the results that aglutenics biscuits (Developed with rice flour $35 \%+$ maize flour $35 \%$ + chickpea flour $30 \%$ ) supplemented with 10-15\% SRB are more suitable for consumption.

Keywords: Coeliac Disease; Aglutenics biscuits; Rice Bran; Storage

Introduction

Biscuits are famous food product consumed by an extensive variety of consumers because of their different taste, long time span of usability and low cost. Due to competition in the business sector and expanded interest for food which is nutritious, natural and have nutraceutical properties, efforts are being made to enhance the nutritional value of biscuits [1]. By altering the ratio of different flours other than wheat and adding up different nutritive ingredients may improve the quality and shelf life of biscuits [2]. Dietary fiber is an important component of food; it improves the probiotic attributes of food products and prevents many diseases. 
Coeliac disease is gluten sensitivity. It is a disease of the small intestine [3]. Celiac disease patients when consume food containing gluten, their immune system responds by damaging the intestinal villi leading to the mal-absorption of nutrients, which in turn adversely affect all the systems of the body [4]. Symptoms of coeliac disease include diarrhea, abdominal cramping and pain. Untreated celiac disease may result in nutrient deficiencies, osteoporosis and other intestinal problems. The only remedy of this disease is to consume gluten-free diet. As per definition "Gluten free food must contain less than 20 ppm of gluten". Gluten provides desirable organoleptic properties to baked and other food products. Without gluten bakery products can't maintain the texture and flavor, this problem could be complemented by adding some substitute flours in different combinations [5]. Gluten free foods are generally low in fiber, protein, vitamins with minimal mineral content and contain pure starch, which gives sandy, dry mouth feel with poor sensory attributes [6].

Rice bran is by product of rice and it holds adequate quantities of fiber. Fiber is an important component of food. For coeliac patients fiber must be included in food to regulate their regular bowl moments because constipation is a main problem in celiac patients. Supplementation of rice bran in gluten free foods may solve this problem [7].

Unfortunately, gluten free food items are not available easily in the shelves especially in developing countries and are expensive. Hence, development of gluten free foods from locally accessible raw materials and ingredients is of utmost importance.
The present study was designed to utilize "stabilized rice bran" for value addition of gluten free biscuits. Biscuits were formulated with rice, chickpea and maize flour, which are highly notorious, easily available and not expensive.

No previous study has been published on the incorporation and quality evaluation of rice bran supplemented gluten free biscuits during storage.

\section{Material and methods}

The study was carried out in the in "Grain Quality Testing Laboratory" of Food Science \& Product Development Institute, National Agriculture Research Centre (NARC) Islamabad".

\section{Collection of raw materials}

To formulate biscuits wheat flour, rice flour, maize flour and chickpea flour; shortening, sugar, eggs, sodium bicarbonate and milk were purchased from the local market of Islamabad. High density polyethylene bags and required chemicals were used from the laboratory stock.

\section{Stabilization of rice bran}

Rice bran is the industrial by-product of rice. It was obtained from National Agriculture Research Centre (NARC) Islamabad. Rice bran (RB) was collected from the "National Agriculture Research Center Islamabad". The milling of rice paddy was done through SATAKE Grain Testing Mill (553500) in Grain Quality Testing Laboratory (GQTL). In this study microwave heating was used to stabilize freshly milled rice bran. Moisture content of rice bran was adjusted to $21 \%$ and microwave heat treatment was given to raw rice bran for 3 minutes [8].

\section{Experimental layout}

The experimental plan used for the present research is given in Figure 1. 


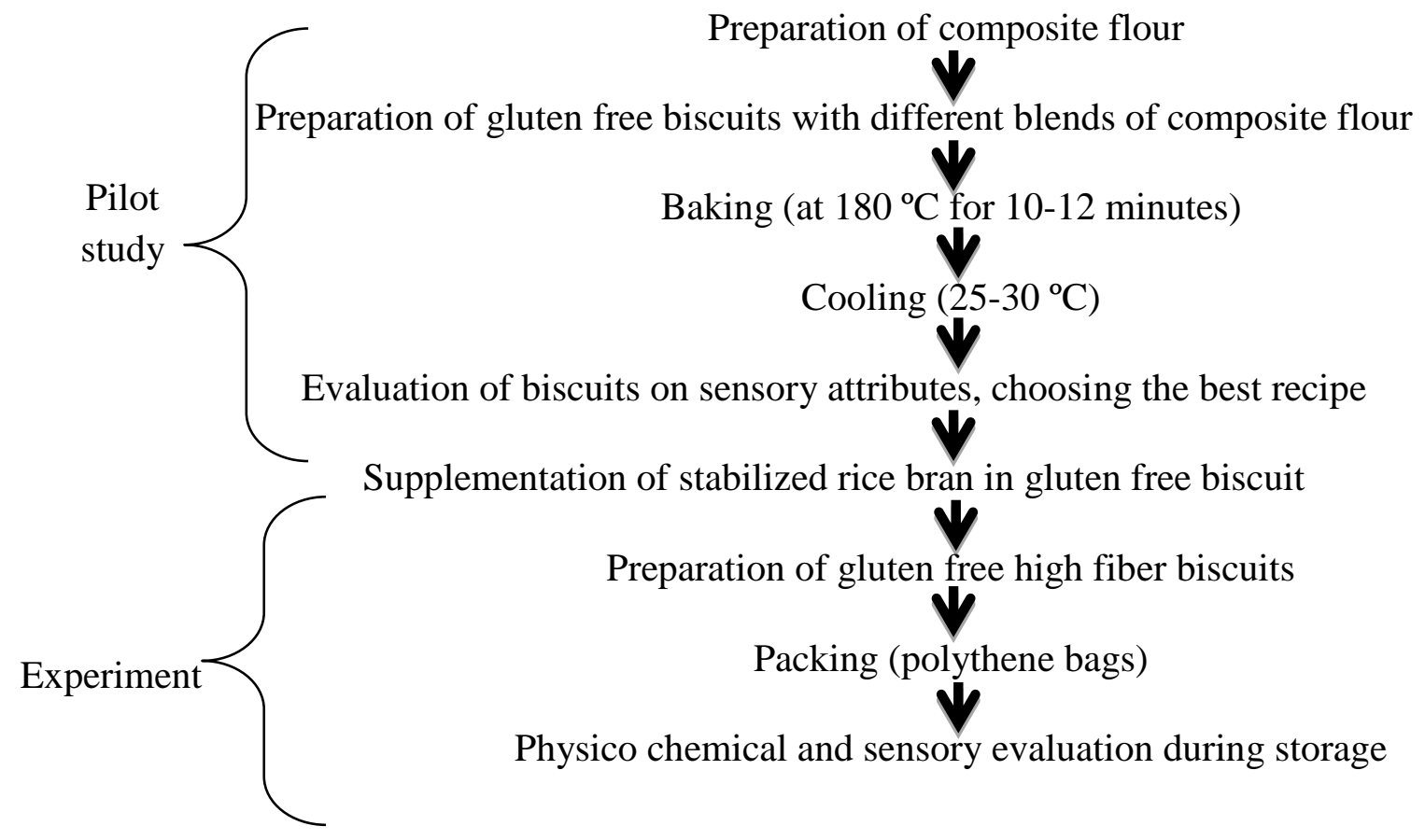

Figure 1. Flow chart of experimental plan

\section{Pilot study}

Formulation and sensory evaluation of gluten free biscuits

Experimental plan of pilot study is given in

Table 1.

In pilot study rice, chickpea and maize flour mixes were used in different quantities to formulate biscuits (Table 2).

Table 1. Experimental plan for pilot study

\begin{tabular}{|c|l|c|l|l|}
\hline S.\# & Parameter & Level & \multicolumn{1}{c|}{ Description of ingredients } \\
\hline 1 & Product Name & 1 & Biscuit flour, rice flour, chickpea flour, shortening, eggs, milk, sugar \\
\hline 2 & Ingredients & 9 & $\begin{array}{l}\text { Maize flour, } \\
\text { powdered, vanilla essence and sodium bicarbonate }\end{array}$ \\
\hline 3 & Treatments & 4 & $\mathrm{~T}_{1}, \mathrm{~T}_{2} \mathrm{~T}_{3}$ and $\mathrm{T}_{4}$ \\
\hline 4 & Analysis & 1 & Sensory analysis \\
\hline
\end{tabular}

Table 2. Treatments Description: Different combination of maize flour, rice flour and chickpea flour for biscuits manufacturing

\begin{tabular}{|l|c|c|c|c|}
\hline Treatments & Wheat $(\%)$ & Rice (\%) & Maize (\%) & Chickpea (\%) \\
\hline $\mathrm{T}_{0}($ Control) & 100 & --- & --- & --- \\
\hline $\mathrm{T}_{1}$ & ---- & 50 & 50 & -- \\
\hline $\mathrm{T}_{2}$ & --- & 45 & 45 & 10 \\
\hline $\mathrm{T}_{3}$ & --- & 40 & 40 & 20 \\
\hline $\mathrm{T}_{4}$ & --- & 35 & 35 & 30 \\
\hline
\end{tabular}

The best recipe/treatment from treatments The selected recipe/treatment was used for main experiment for the supplementation of different levels of rice bran $(5 \%, 10 \%$, and $15 \%$ ) to develop gluten free high fiber biscuits for coeliac patients. (Table 2) was evaluated on sensory basis. 


\section{Main experiment}

To evaluate the effect of stabilized rice bran on the quality of gluten free Biscuits.

The Experimental plan of "Main Experiment" is given below (Table 3).
From pilot study (Table 2) selected recipe/treatment of biscuits was subjected to supplementation of different concentrations of stabilized rice bran (Table 4) to make the biscuits more healthy and palatable.

Table 3. Experimental plan for main experiment

\begin{tabular}{|c|l|c|l|}
\hline S. \# & \multicolumn{1}{|c|}{ Parameters } & Levels & \multicolumn{1}{|c|}{ Description of ingredients } \\
\hline 1. & Product Name & 1 & Biscuit \\
\hline 2. & Ingredients & 8 & $\begin{array}{l}\text { Selected Composite flour mix, rice bran , } \\
\text { shortening, eggs, milk, sugar powdered, vanilla } \\
\text { essence and sodium bicarbonate }\end{array}$ \\
\hline 3. & Treatments & 4 & $\mathrm{~T}_{0}, \mathrm{~T}_{1}, \mathrm{~T}_{2}$ and $\mathrm{T}_{3}$ \\
\hline 4. & Analysis & 3 & $\begin{array}{l}\text { Chemical analysis, physical analysis \&sensory } \\
\text { analysis }\end{array}$ \\
\hline 5. & Packaging material & 1 & High Density Poly Ethylene \\
\hline 6. & Storage temperature & 1 & Ambient/room temperature \\
\hline 7. & Storage duration & & 8 weeks \\
\hline
\end{tabular}

Table 4. Treatments description (main experiment): Supplementation of stabilized rice bran in selected composite flour recipe

\begin{tabular}{|c|c|c|}
\hline Treatment & Composite flour $(\mathbf{g})$ & Rice bran $(\mathbf{g})$ \\
\hline $\mathrm{T}_{0}$ & 100 & ------ \\
\hline $\mathrm{T}_{1}$ & 95 & 5 \\
\hline $\mathrm{T}_{2}$ & 90 & 10 \\
\hline $\mathrm{T}_{3}$ & 85 & 15 \\
\hline
\end{tabular}

\section{Chemical evaluation}

Moisture (\%), ash (\%), crude protein (\%) and crude fiber content $(\%)$ were analyzed by the methods of [9].

\section{Physical evaluation}

Biscuits were evaluated for width (mm), thickness (mm) and spread factor by following the procedures of [10].

\section{Sensory evaluation}

The panel evaluated four randomly given biscuit samples for color, flavor, texture and overall acceptability. using an $10-\mathrm{cm}$ unstructured line scale was used for each panelist on the sensory survey and the panelists placed a vertical mark on the scales according to their observation of each sensory attribute ranging from zero (0) denoting extremely disliked to (9) denoting extreme (e.g. extremely liked). The descriptive analysis of the biscuits was replicated three times with a fresh batch each time. A panel of 26 panelists (male and female 50:50) in the age range of 20-50 years. The panelists were guided according to guidelines in ISO/5496 [11]. In between samples, panelists were served drinking water to cleanse their mouths. Before engaging in the sensory analysis the panelists were informed about the nature of the biscuit samples they would evaluate. Biscuits were evaluated by the method of [12]. 


\section{Statistical analysis}

The data were statistically analyzed by using Analysis of Variance (ANOVA) and Least Significant Difference (LSD) was applied for mean separation at $5 \%$ probability level by the method of [13].

Results and discussion
Proximate composition of wheat flour, rice flour, maize flour, chickpea flour and rice bran

Before conducting the study sample of raw material was analyzed for proximate composition viz. fiber (\%), ash (\%), protein (\%) and moisture content (\%), Table 5.

Table 5. Proximate composition of raw materials

\begin{tabular}{|c|c|c|c|c|}
\hline Raw material & Fiber (\%) & Ash $(\boldsymbol{\%})$ & Protein $(\boldsymbol{\%})$ & Moisture (\%) \\
\hline Wheat & $0.80 \pm 0.045$ & $0.50 \pm 0.200$ & $10.06 \pm 0.118$ & $12.69 \pm 0.210$ \\
\hline Rice & $0.16 \pm 0.055$ & $1.32 \pm 0.030$ & $2.60 \pm 0.065$ & $10.03 \pm 0.229$ \\
\hline Maize & $2.02 \pm 0.090$ & $2.11 \pm 0.055$ & $9.00 \pm 0.055$ & $9.70 \pm 0.300$ \\
\hline Chickpea & $1.28 \pm 0.060$ & $2.64 \pm 0.060$ & $19 \pm 0.095$ & $10.03 \pm 0.152$ \\
\hline Rice bran & $7.68 \pm 0.070$ & $8.56 \pm 0.140$ & $14.65 \pm 0.105$ & $9.56 \pm 0.115$ \\
\hline
\end{tabular}

Values are mean \pm standard deviation of triplet determinations

\section{Pilot study}

A pilot study was conducted, composite flour biscuits were evaluated on sensory basis and best combination was selected for further studies (Figure 2). The results of pilot study are given. Sensory evaluation of aglutenics biscuits showed that maximum color score was recorded for $\mathrm{T}_{4}$ (rice flour $35 \%$ + maize flour $35 \%$ + chickpea flour $30 \%)$. While, minimum color score was recorded for $\mathrm{T}_{1}$ (rice flour $50 \%+$ maize flour $50 \%+$ chickpea flour $0 \%$ ). It was observed that as the chickpea flour level increased it gave nice brown color to biscuits (figure 3). The results are in agreement with the results of [14]. The reason might be high protein content of chickpea, when amino acids react with reducing sugar during baking of biscuits Millard reaction takes place which gave darker color to biscuits (Figure 3). The data depicted that flavor scores increased significantly with treatments. The highest score (8.23) for flavor was recorded for $\mathrm{T}_{4}$ (rice flour $35 \%+$ maize flour $35 \%+$ chickpea flour $30 \%$ ), the results are supported by the results of [15].It was observed that highest taste score (8.10) was noted for $\mathrm{T}_{4}$ (rice flour $35 \%$ + maize flour $35 \%+$ chickpea flour $30 \%$ ) and the lowest taste score (5.80) was noted for $\mathrm{T}_{1}$ (rice flour $50 \%$ + maize flour $50 \%$ + chickpea flour $0 \%$ ). These results are in collaboration with the finding of [16]. They observed that the increase in taste score with the increase in chickpea flour might be due to sweet beany aftertaste of chickpea flour which was liked by the panelists. The maximum texture score (8.66) was recorded for $\mathrm{T}_{4}$ (rice flour $35 \%$ + maize flour $35 \%$ + chickpea flour $30 \%)$. While, minimum texture score (5.50) was recorded for $\mathrm{T}_{1}$ (rice flour $50 \%+$ maize flour $50 \%$ ). Similar results were observed by [4]. They reported that chickpea flour has high water binding capacity and hence it gave better texture to composite flour biscuits. Overall acceptability scores were determined on the basis of quality scores obtained from the evaluation of color, flavor, taste and texture of the gluten free biscuits. Among all the treatments, the highest color, flavor, taste, texture and overall acceptability scores were recorded for $\mathrm{T}_{4}$ which contained (rice flour $35 \%+$ maize flour $35 \%+$ chickpea flour $30 \%$ ). 
On the sensory basis $\mathrm{T}_{4}$ (rice flour $35 \%+$ maize flour $35 \%$ + chickpea flour $30 \%$ ) was selected for supplementation of heat stabilized rice bran $(5,10$, and $15 \%)$ for making more nutritional and healthy gluten free high fiber biscuits for celiac disease patients.

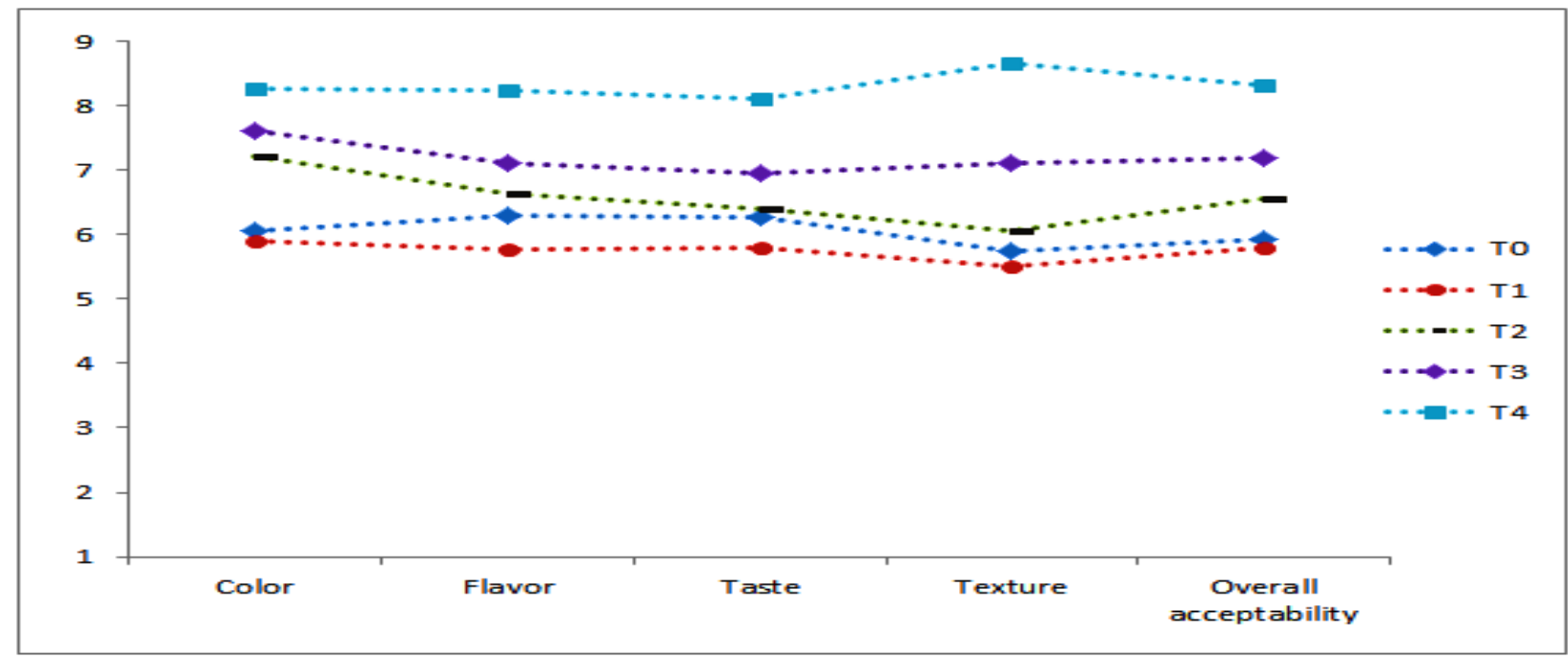

Figure 2. Sensory evaluation of gluten free biscuits

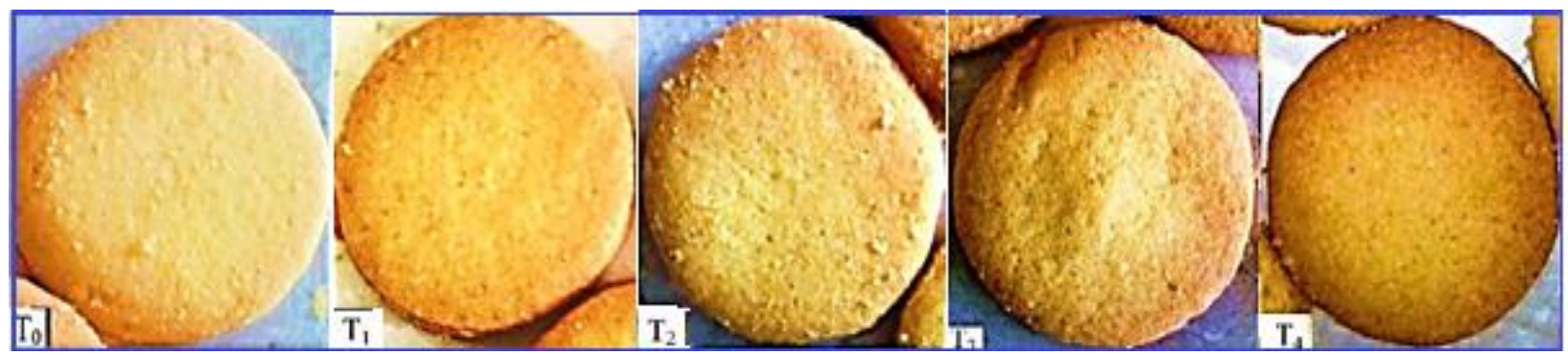

Figure 3. Effect of composite flour levels on the appearance of gluten free biscuits

Main experiment: Effect of stabilized rice bran (SRB) supplementation on quality of gluten free composite flour biscuits

The gluten free high fiber biscuits prepared from composite flours (rice, maize, chickpea) and stabilized rice bran were analyzed for their chemical and sensory attributes. The results obtained during the research study are presented here-in-after.

Chemical evaluation of gluten free high fiber biscuits

Moisture content is key factor which determines the quality and shelf life of product. The data revealed that moisture (\%) of gluten free biscuits was significantly increased with SRB (Figure 4).The significantly highest moisture was observed in treatment $\mathrm{T}_{3}(15 \%$ rice bran), while significantly lowest moisture was found in $\mathrm{T}_{0}$ (no rice bran). The results are in collaboration with the results of [14] who highlighted that rice bran contains cellulose and other non-starch polysaccharides which hold moisture which contains much higher moisture \% than its own weight, therefore as the concentration of rice bran increased the moisture $\%$ of biscuits increased. Data related to storage stability of biscuits revealed that moisture $\%$ of biscuits increased significantly with the storage. These results are in accordance with the results of [15]. 
The ash content of any food item is related to its mineral content. Ash content is an indicator of total mineral content present. The results illustrated that ash content (\%) differed significantly among the treatments (Figure 5). Ash content was increased with rice bran. The significantly highest ash content was found in $\mathrm{T}_{3}(15 \%$ rice bran) followed by $\mathrm{T}_{2}$ (10\% rice bran), $\mathrm{T}_{1}$ ( $5 \%$ rice bran) and $\mathrm{T}_{0}$ (non-supplemented biscuits). The results of [16] are in accordance with these results, who observed that supplementation of different levels of rice bran in biscuits significantly increased the ash content (\%). The reason might be higher ash content of rice bran. The data revealed that during storage the ash content (\%) observed at zero day was significantly differ from other treatments during storage. While values for ash content at 15,30, 45 and 60 days were statistically at par. Same trend was observed by [17]. The data depicted that these composite flour high fiber biscuits can be considered nutritionally superior than wheat flour biscuits.

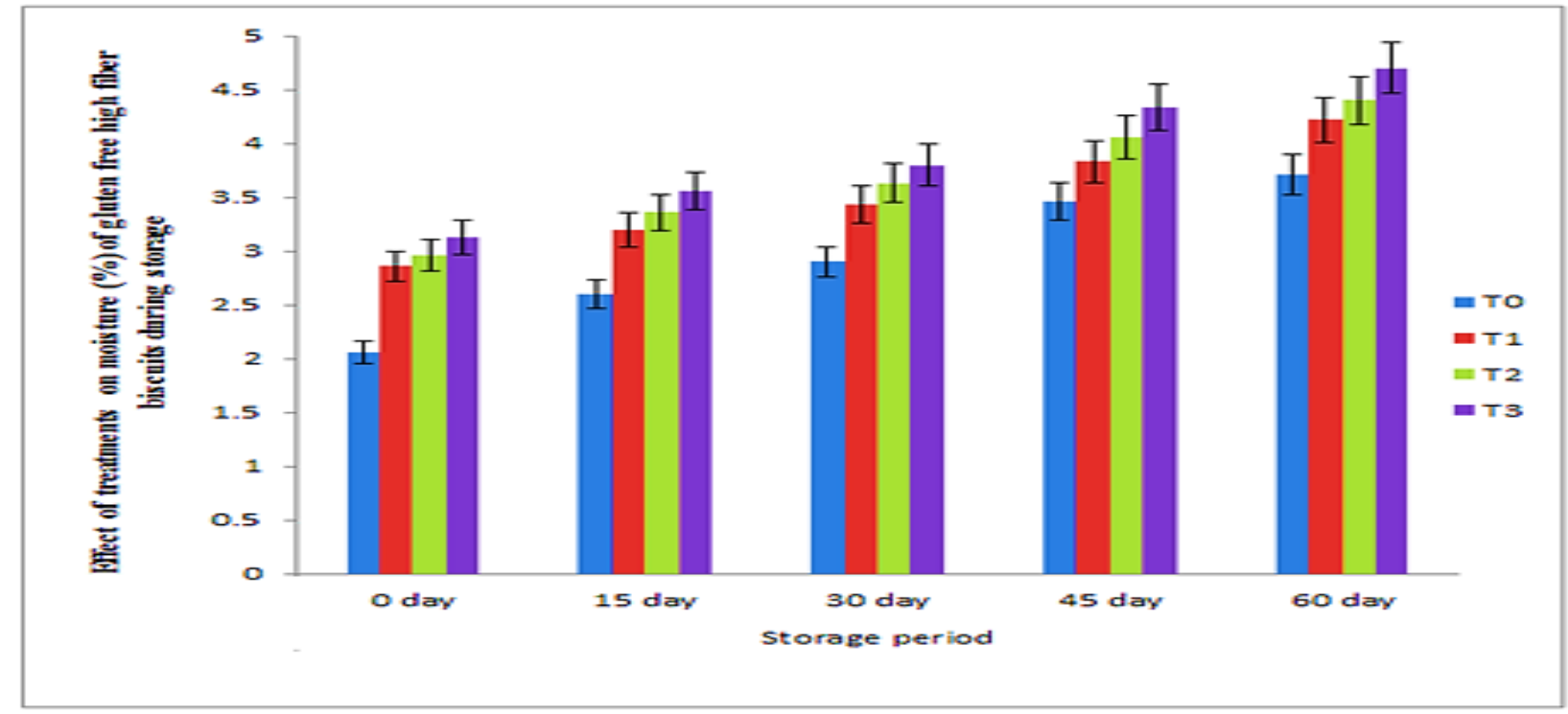

Figure 4. Effect of bran levels on moisture (\%) of gluten free high fiber biscuits during storage

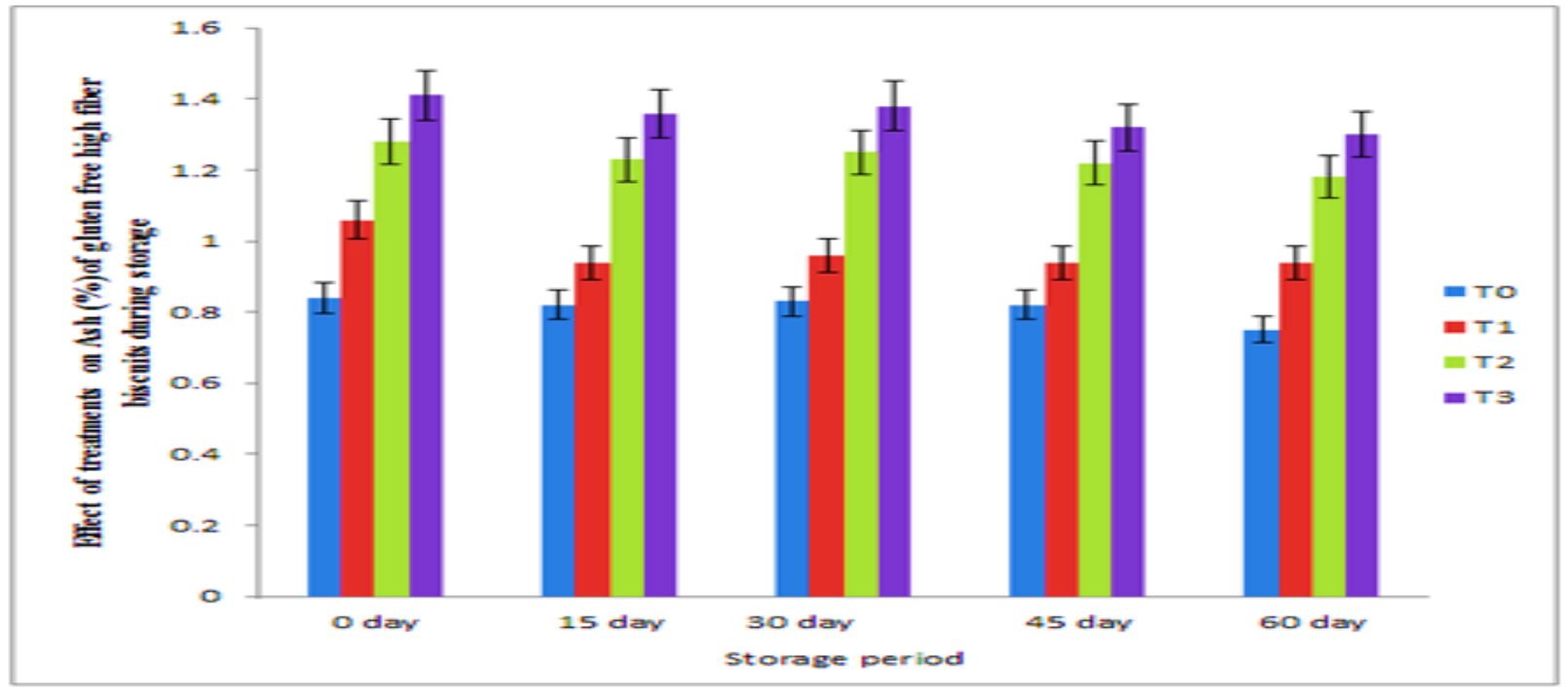

Figure 5. Effect of bran levels on ash (\%) of gluten free high fiber biscuits during storage 
Currently, the significance of consuming dietary fiber has enhanced due to its effect on blood cholesterol levels and occurrence of colon cancer. Recommended total dietary fiber intake is above $25 \mathrm{~g} /$ day $[18,19]$. Fiber content of biscuits increased with the increased levels of SRB (Figure 6).The significantly maximum fiber content was found in $\mathrm{T}_{3}(15 \%$ rice bran).While, significantly lowest fiber content was found in $\mathrm{T}_{0}$ (non-supplemented biscuits).Similar trend was observed by [17] in rice bran supplemented cookies. It was also observed that fiber (\%) was significantly decreased during storage. These results are supported by [19] who observed similar trend.

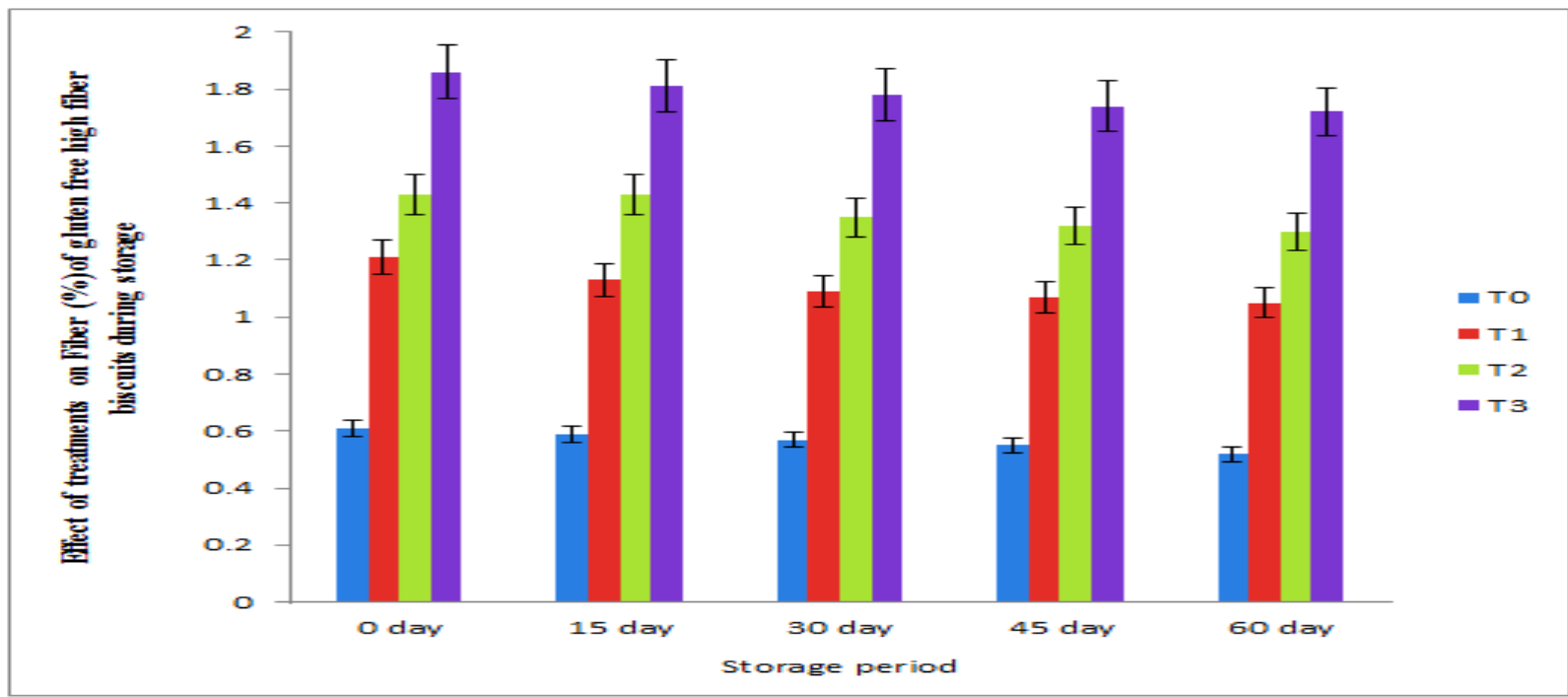

Figure 6. Effect of bran levels on fiber (\%) of gluten free high fiber biscuits during storage

Protein content $(\%)$ of biscuits was affected significantly due to supplementation of different levels of rice bran. The increase in protein content of biscuits with treatments may be ascribed to the higher protein content of rice bran (Figure 7). With the increase in concentration of stabilized rice bran, protein content of gluten free biscuits increased accordingly. The significantly highest protein (\%) was found in treatment $\mathrm{T}_{3}$ (15\% rice bran). While, significantly lowest protein content was found in $\mathrm{T}_{0}$ (control). The similar trend was also observed by [19]. However, protein content decreased significantly with storage. The decrease in the protein content of gluten free high fiber biscuits during storage might be due to the proteolysis activity of the enzymes as well as water absorption during storage [20].

Physical evaluation of gluten free high fiber biscuits during storage

Physical evaluation of biscuits is very significant characteristic to assess its quality. Too much thin or thick biscuits are not liked by the consumers. Results suggested that supplementation of various levels of rice bran has significant effect on width, thickness and spread factor of biscuits storage.

\section{Width (mm)}

On the index of physical characteristics width of gluten free biscuits was significantly affected by the supplementation levels of rice bran (Figure 8). The results elucidated that $\mathrm{T}_{0}$ (non-supplemented biscuits) exhibited maximum width, while minimum width was 
noted in $\mathrm{T}_{3}$ (15\% rice barn). [20] also observed same trend. They found decreasing trend of width with proportionate increase of rice bran level. It was also observed that width of the biscuits decreased significantly during storage. These results are in accordance with the findings of [16] who noticed that width of rice bran supplemented biscuits decreased during storage might be due to temperature and humidity.

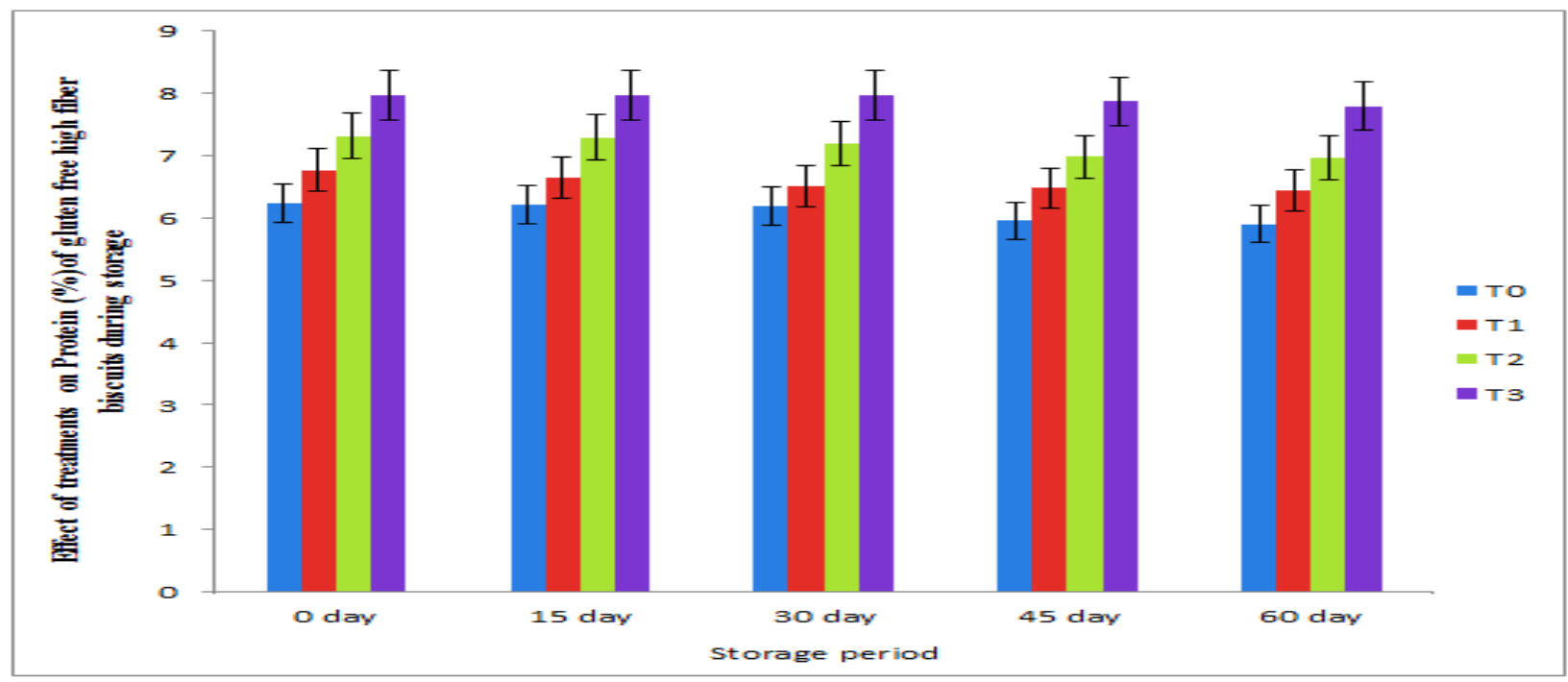

Figure 7. Effect of bran levels on protein (\%) of gluten free high fiber biscuits during storage

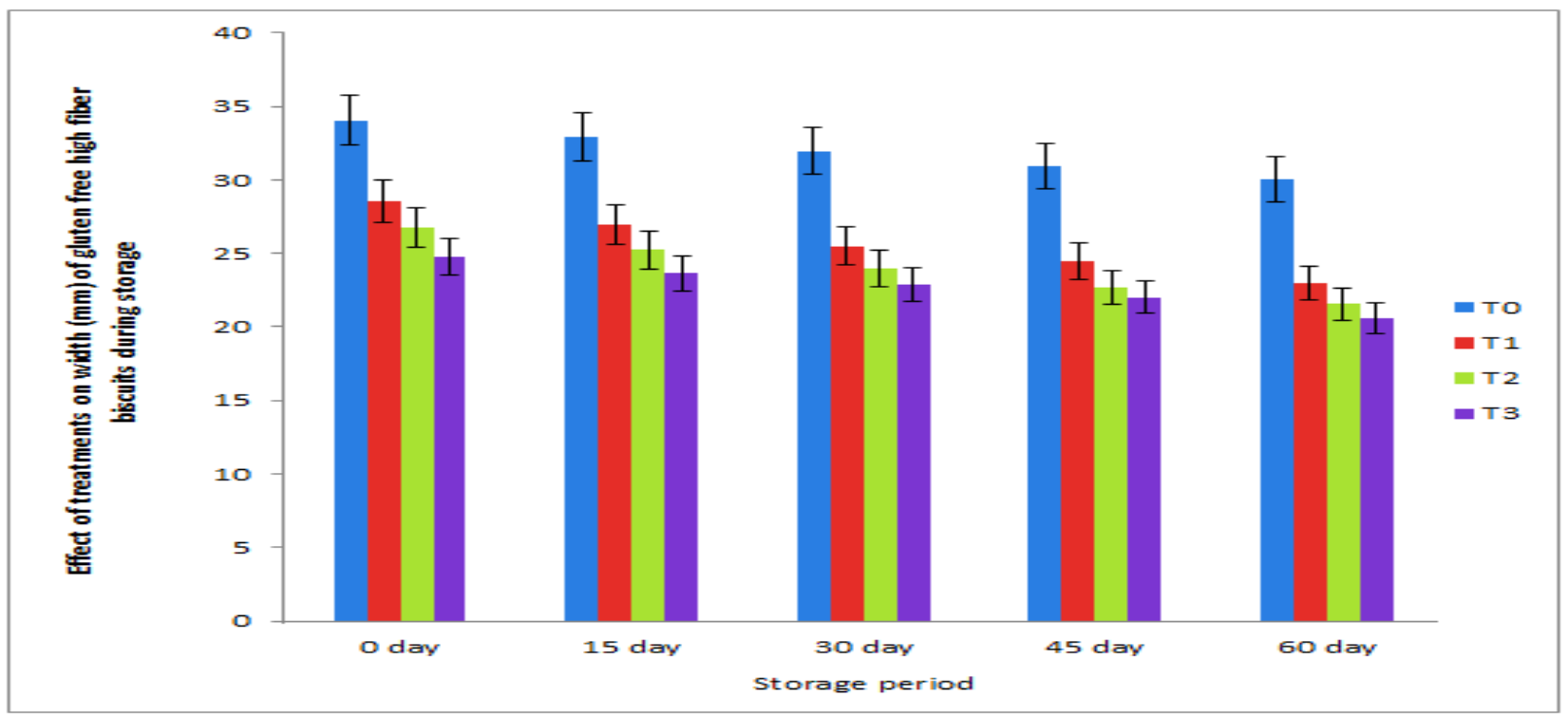

Figure 8. Effect of bran levels on width $(\mathrm{mm})$ of gluten free high fiber biscuits during storage

\section{Thickness (mm)}

The data depicting the means for thickness of biscuits is shown in figure 9. The mean scores reveled increasing trend of thickness with proportionate increase of SBR levels.
The results elucidated that $\mathrm{T} 3$ (15\% rice bran) exhibited maximum thickness, while minimum thickness was observed in $\mathrm{T}_{0}$ (non-supplemented biscuits). [21] Found that thickness of biscuits increased with 
increasing levels of protein content and rice bran is rich source of protein. Results related to storage duration illustrated that thickness of biscuits decreased with the storage intervals. However, the change was non-significant. The same results were noted by [22].

\section{Spread factor}

There was a decreasing trend in the spread factor of biscuits prepared with different levels of rice bran supplementation. The maximum mean value for spread factor was observed in $\mathrm{T}_{0}$ (non-supplemented biscuits), whereas minimum spread factor was found in biscuits prepared with $15 \%$ rice bran supplementation (Figure 10). These results are supported by the findings of [16-18], who observed a decreasing trend in spread ratio of biscuits with the increase in the levels of rice bran. They reported that rice bran supplemented in biscuits upto $10 \%$ was considered suitable for use.

\section{Sensory evaluation of gluten free high} fiber biscuits

The results of sensory evaluation of biscuit recipes supplemented with SRB revealed pleasing acceptance of gluten free biscuits for most of the characteristics viz. color, taste, flavor, texture and overall acceptability. In baking, color is very important attribute.

Color of biscuits is found to be correlated with flavor and aroma. Sensory evaluation of biscuits emphasized that scores for color of biscuits decreased significantly with increase in levels of SRB from light brown to dark brown, leading to lower acceptance (Figure 11). Highest mean color scores for treatments showed that maximum color scores were found for $\mathrm{T}_{0}(0 \% \mathrm{SRB})$, followed by $\mathrm{T}_{1}(5 \% \quad \mathrm{SRB})$ and $\mathrm{T}_{2}(10 \%$ $\mathrm{SRB})$ which were statistically alike. While, minimum color score was found for $\mathrm{T}_{3}(15 \%$ SRB).The results are supported by the results of [23] who reported that progressive increase in supplementation level of $\mathrm{RB}$ produced progressively darker biscuits. The darker color may result due to the caramelization, dextrinisationor nonenzymatic browning (Maillard reaction) between reducing sugar molecules and lysine protein [24]. It was observed that during storage the biscuits turned darker. The decrease in color score of biscuits might be due to moisture absorption during storage which may lead to fat oxidation [25].

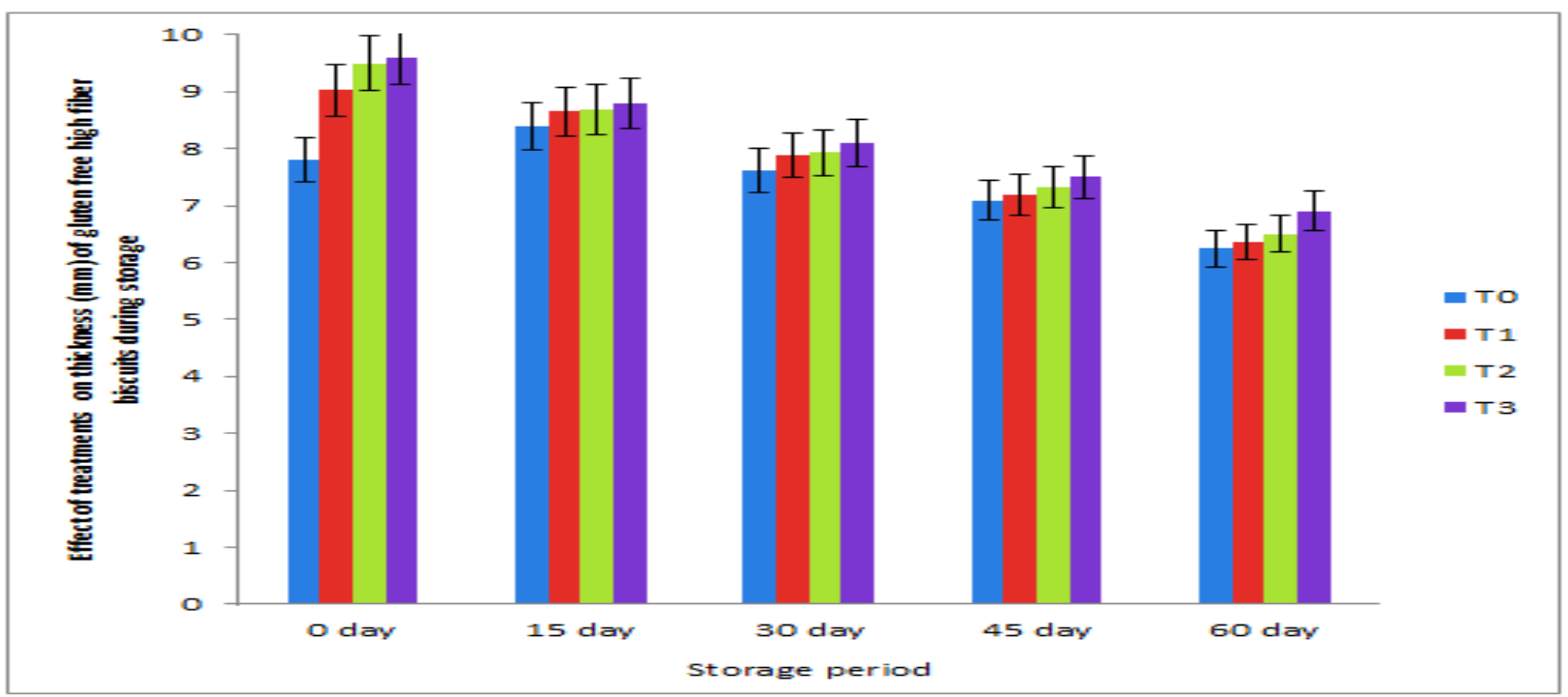

Figure 9. Effect of bran levels on thickness $(\mathrm{mm})$ of gluten free high fiber biscuits during storage 


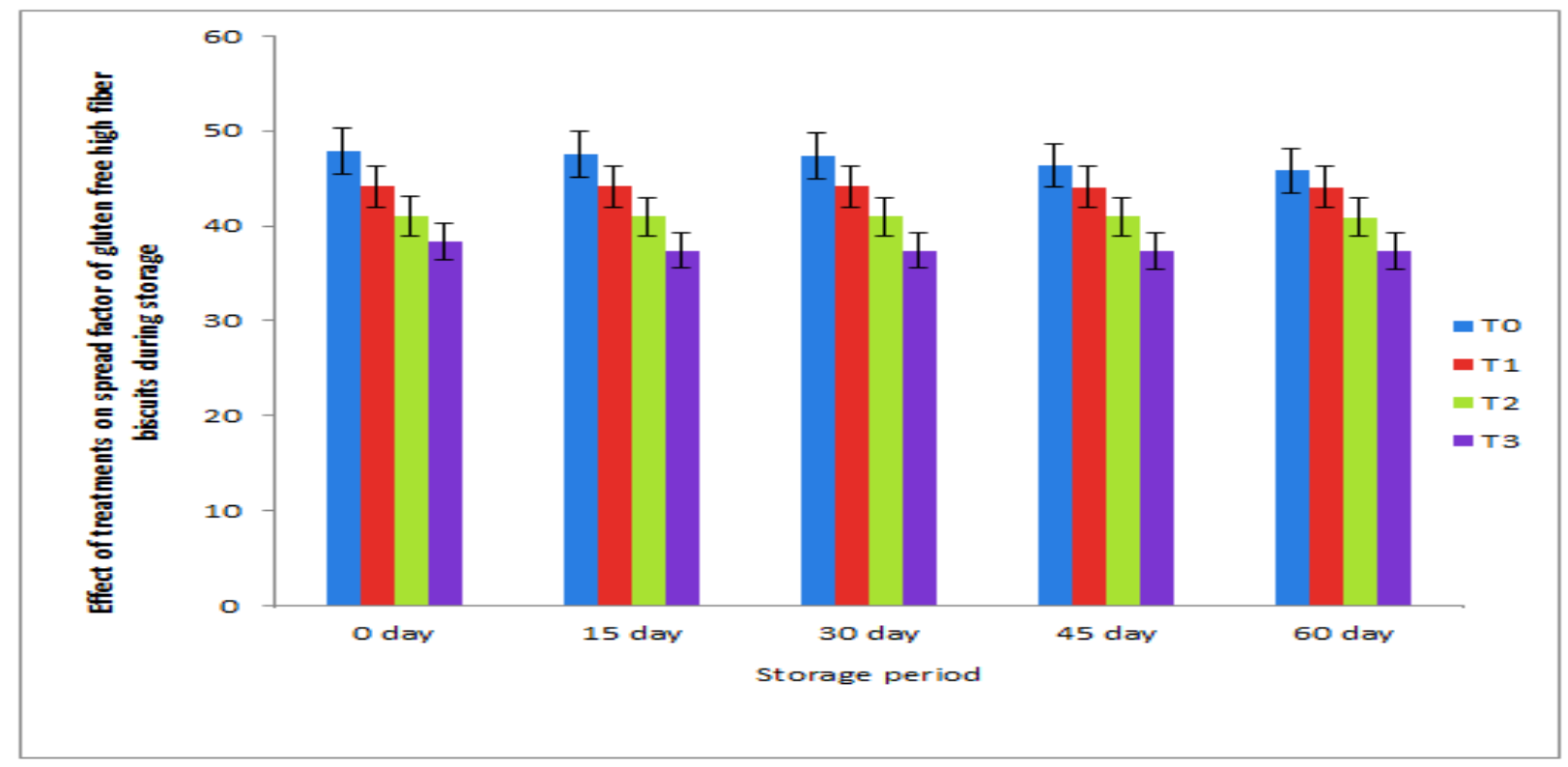

Figure 10. Effect of bran levels on spread factor of gluten free high fiber biscuits during storage

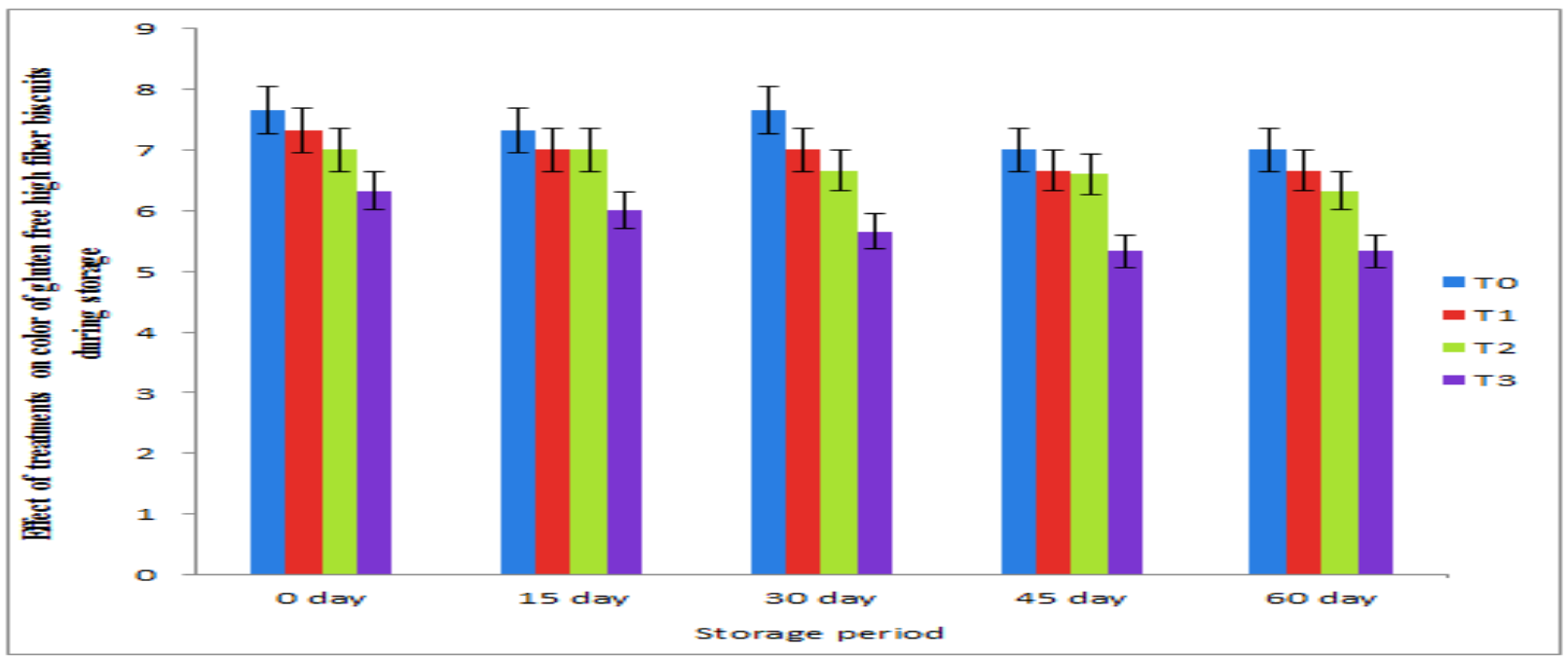

Figure 11. Effect of bran levels on color of gluten free high fiber biscuits during storage

Taste is very important attribute; it is influenced by texture, flavor and composition of the product (Figure 12). The mean scores for taste of biscuits differed significantly among the control and treated samples. It was evident from the data that maximum texture score was observed for $\mathrm{T}_{0}$ followed by $\mathrm{T}_{1}$ and $\mathrm{T}_{2}$. While, $\mathrm{T}_{3}$ attained minimum taste scores among all the treated samples. It was also observed that effect of storage on SRB biscuits was significant. Maximum taste score was assigned to fresh biscuit samples which were gradually decreased after 60 day storage. The decrease in taste score of biscuits was might be due to the rancidity of fats during storage [20]. 


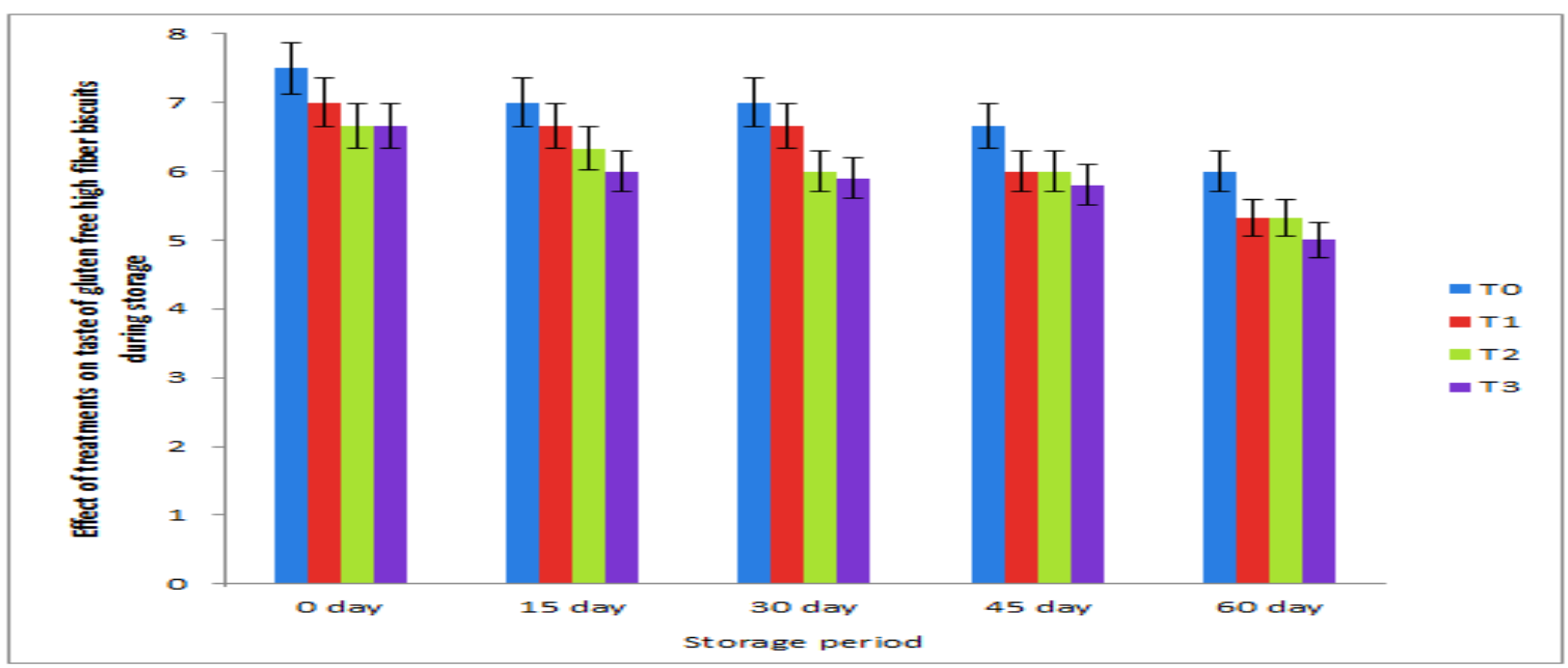

Figure 12. Effect of bran levels on taste of gluten free high fiber biscuits during storage

Texture is an important factor which affects the consumer acceptance of the product. The gluten free biscuits when consumed should give a biscuit eating feeling to consumer than only the product will be acceptable. Mean scores for texture of biscuits were found to be differed significantly (Figure 13). The significantly highest texture score was obtained for $\mathrm{T}_{0}$ (non-supplemented biscuits) followed by $\mathrm{T}_{1}(5 \% \mathrm{SRB})$ and $\mathrm{T}_{2}(10 \%$
SRB) which were statistically at par. While, significantly lowest texture score was observed in $\mathrm{T}_{3}$ (15\% rice bran). The data also showed that storage significantly affected the texture score of biscuits. The findings of present study were supported by the findings of [21] who observed that texture score of biscuits decreased significantly during storage due to absorption of moisture and loss of crispiness of biscuits.

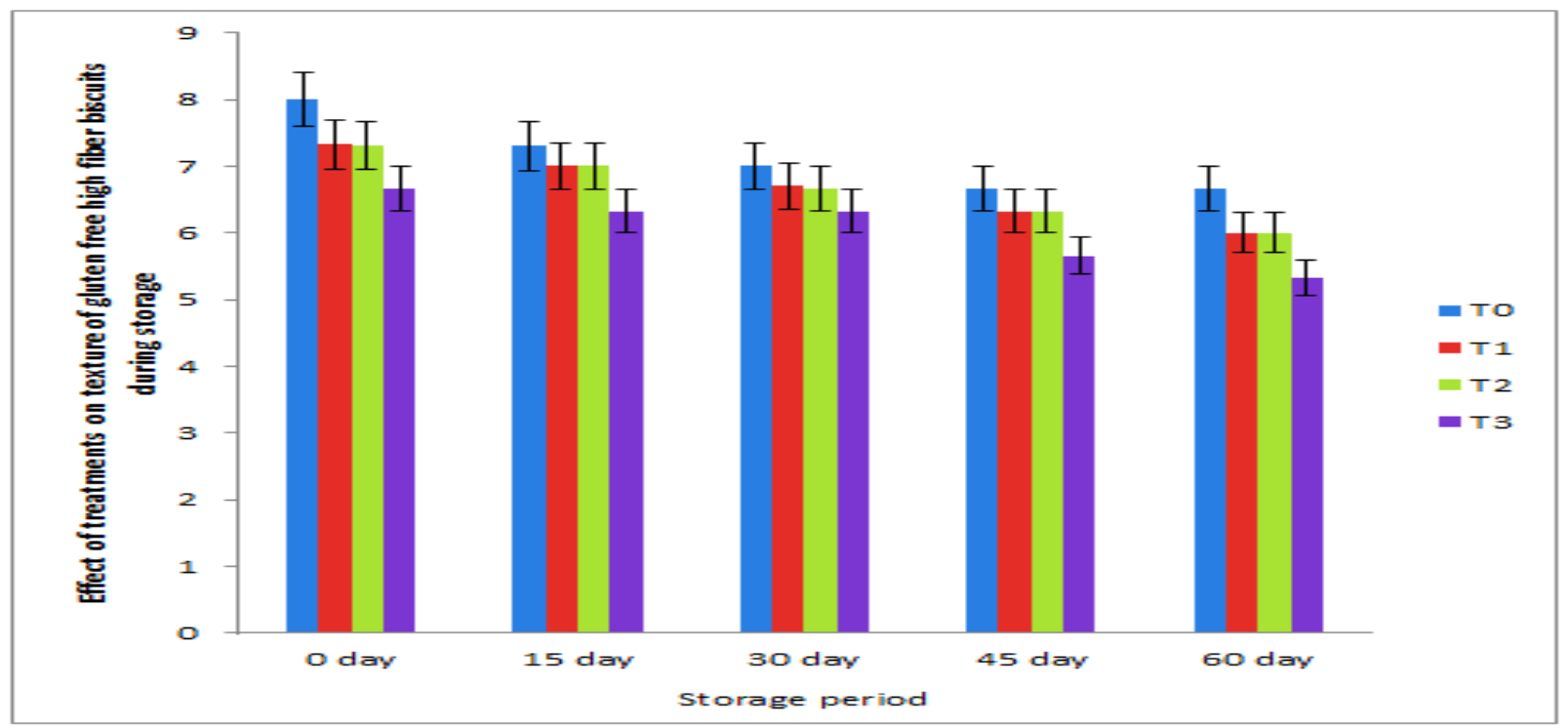

Figure 13. Effect of bran levels on texture of gluten free high fiber biscuits during storage 
The data regarding to overall acceptability of gluten free biscuits reveled that highest scores for overall acceptability were recorded for $\mathrm{T}_{0}$ (control treatment). Among the treated samples $\mathrm{T}_{2}(5 \% \mathrm{SBR})$ and $\mathrm{T}_{3}$ (10\% SBR) attained the maximum scores by the panelists, these two treatments were statistically at par. Minimum overall acceptability was found for $\mathrm{T}_{3}$ (figure
14). These results are in agreement with the findings of [20] who found the similar results in soy flour and rice bran biscuits. Henceforth, it is concluded from the results of sensory evaluation of biscuits that supplementation of SRB at the level of 5-10 percent is more suitable for production of rice bran supplemented gluten free flour biscuits.

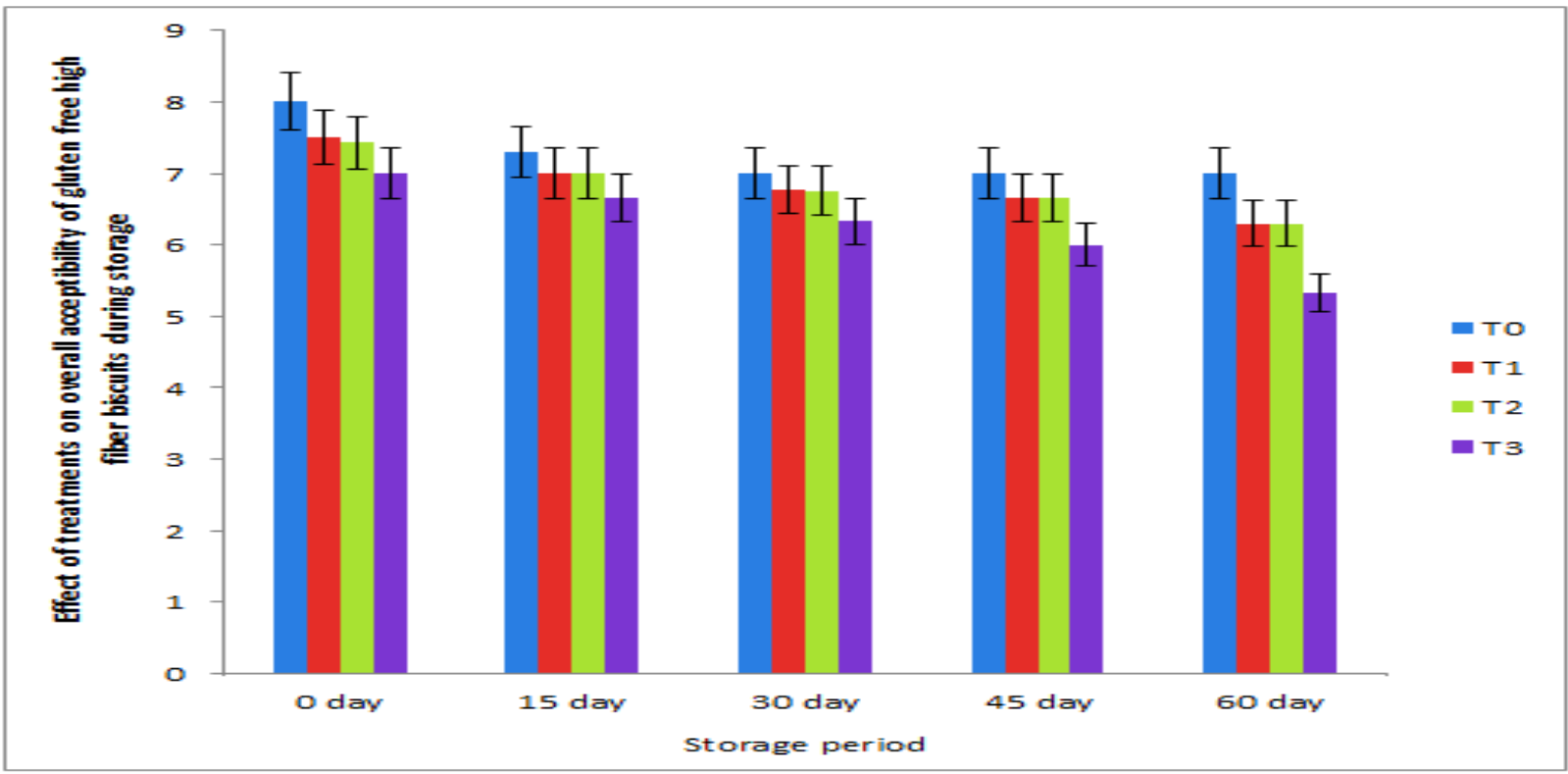

Figure 14. Effect of bran levels on overall acceptability of gluten free high fiber biscuits during storage

\section{Conclusions}

It can be concluded from the results of present research study that gluten-free biscuits can be developed by non-wheat composite flours such as: rice flour, maize flour and chickpea flours. The main problem with gluten free biscuits is their poor sensory properties. The blend consisting of rice flour $35 \%+$ maize flour $35 \%+$ chickpea flour $30 \%$ was successfully used for gluten-free biscuits preparation without any adverse effect on the sensory characteristic of biscuits. Furthermore, biscuits were nutritionally rich. It was found that addition of rice bran (5-10\%) leads to biscuits with good nutritional and sensorial properties with high fiber content.
Authors' contributions

Conceived and designed the experiments: $S$ Javaria, Performed the experiments: A Karim \& A Mumtaz, Analyzed the data: M waqas \& K Waseem, Contributed reagents/ materials/ analysis tools: S Raza, Wrote the paper: S Javaria.

\section{References}

1. Lubna M VA \& Bashir K (2012). Fortification of Biscuit with Flaxseed: Biscuit Production and Quality Evaluation. $J$ Toxicol and Food Technol 1(5): 6-9.

2. Ahmed M, Hussein S, Nefisa A, Hegazy K, Thanaa A \& Ibrahim A (2012). Production and Evaluation of Gluten-Free Cakes. Australian J Basic and Applied Sci 6(12): 482-491. 
3. Hamer RJ (2005). Coeliac Disease: Background and biochemical aspects. Biotech Adv 23(6): 401-408.

4. Noor AA, Noor YM \& Ho LH (2012). Physicochemical and organoleptic properties of cookies incorporated with legume flour. Int Food Res J 19(4): 1539-1543.

5. Jay H, Janz M \& Gerlat M (2010). Development of gluten-free cracker snacks using pulse flours and fractions. Food Res Int 43(2): $627-633$.

6. Okpala LCE, Okoli C (2011). Nutritional evaluation of cookies produced from pigeon pea, cocoyam andsorghum flour blends. African. J. Biotechnol 10(3): 433-438.

7. Neha M \& Chandra R (2012). Development of functional biscuit from soy flour \&rice bran. Int. J. Agric and Food Sci 2(1): 14-20.

8. Kurniawati MN, Yuliana D \& Budijanto $S$ (2014). The effect of single screw conveyor stabilization on free fatty acids, $\alpha$-tocoferol, and $\gamma$ - oryzanol content of rice bran. Int Food Res J 21(3): 1201-1205.

9. AACC (2000). Approved Methods of American Association of Cereal Chemists. Am. Assoc. Cereal Chem. Inc., St. Paul., Minnesota, USA.

10. AOAC (2005). Official Methods of Analysis. 18th ed. Association of Official Analytical Chemists, Virginia, USA.

11. ISO 11035 (1994). Sensory analysis. Identification and selection of descriptors for establishing a sensory profile by a multidimensional approach.

12. Larmond E (1997). Laboratory Methods for Sensory Evaluation of Foods," Canada Department of Agriculture Publication. Ottawa.

13. Steel RGD, Torrie H \& Dickey D (1997). Principles and Procedures of Statistics. A biometrical approach, $3^{\text {rd }}$ Ed. McGraw Hill Book Company Inc., New York.

14. Siddique HN, Raza S \& Hameed T (2003). Sensory and physical evaluation of biscuits supplemented with soy flour. Pak J Food Sci 13(1-2): 45-48.
15. Sharoba AM, Abd El-Salam AM \& Hoda H (2014). Production and evaluation of gluten free biscuits as functional foods for celiac disease patients. J Agroalimentary Process \& Technologies 20(3): 202-2014.

16. Dhingra \& Jood S (2002). Organoleptic and nutritional evaluation of wheat breads supplemented with soybean and barley flour. Food Chem 77(4): 479-488.

17. Younas A, Bhatti S, Ahmed A \& Randhawa MA (2011). Effect of rice bran supplementation on cookie baking quality. Pak J Agric Sci 48(2): 129-134.

18. Sharif MKM, Butt SF, Anjum M and Nawaz H. 2009. Preparation of Fiber and Mineral Enriched Defatted Rice Bran Supplemented Cookies. Pak J Nutri 8(5): 571-577.

19. WHO/UNSCN (2007). Fifth Report on the World Nutrition Situation: Nutrition for Improved Development Outcomes.

20. Sharma HR \& Chauhan GS (2002). Effect of stabilized rice bran fenugreek blends on the quality of breads and cookies. J Food Sci Nutri 39:225-233.

21. Shiv K, Rekha LL, Sinha K (2010). Evaluation of quality characteristics of soy based millet biscuits. Adv Applied Sci Res 1(3): 187-196.

22. Sudha ML, Vetrimani R \& Leelavathi K (2007). Influence of fibre from different cereals on the rheological characteristics of wheat flour dough and on biscuit quality. Food Chem 100(4): 1365-1370.

23. Manley D (2002). Technology of Biscuits, Crackers and Cookies, 3rd ed. Woodhead Pub. Ltd., Cambridge.

24. Mian K, Masood S, Butt S, Anjum MF and Nawaz H. 2009. Preparation of Fiber and Mineral Enriched Defatted Rice Bran Supplemented Cookies. Pak J Nutri 8 (5): 571-577.

25. Srivastava YA, Semwal D, Sharma GK, Bawa AS (2010). Effect of virgin coconut meal on the textural, thermal and physico chemical properties of biscuits. Food and Nutri Sci 2: $38-44$. 